\title{
An Immune Based Multi-Objective Approach To Enhance the Performance of Electrical Distribution System
}

\author{
${ }^{1,2}$ Sreenidhi Institute of Science and Technology, Hyderabad, India \\ Email: ravi.dsm@gmail.com, ganduribharathi@gmail.com
}

\section{Received: $2^{\text {th }}$ December 2017, Accepted: 20th January 2018, Published: $\mathbf{2 8}^{\text {th }}$ February 2018}

\begin{abstract}
An immune based approach to enhance the performance of electrical distribution system through capacitor placement is proposed in this paper. Major challenges that occur in distribution system are voltage drop and real power losses. The placement and sizing calculations of capacitor gives more insight to solve problems, which occur while maintaining voltage profiles at each bus by reducing voltage drops in each branch. The performance of the electrical distribution system can be improved with the above proposed technique. This technique have two sub methods, one for finding capacitor location through heuristic and second one for finding capacitor size through genetic algorithm and the proposed methods are tested on IEEE 33 and 69 bus systems to reduce the real power losses with better voltage profile at each load buds and the results are validated.
\end{abstract}

Keywords: Heuristic method, Genetic algorithm, Loss sensitivity factor, Voltage drop, Real power loss, Capacitor placement and size.

\section{Introduction}

Around $33 \%$ of the engendered power is wasted as heat during distribution of puissance. The presence of reactive elements further increases authentic and reactive power losses since they draw more current than resistive elements. Hence in order to amend efficiency of the distribution system, capacitor banks are to be placed at congruous locations.

The placement of capacitor banks additionally amends the voltage profile of the system. Thus the capacitor bank placement is vital for power flow control, ameliorating system stability, power factor rectification, voltage profile management and the reduction in energy losses.

Capacitor placement is used to minimize active and reactive power losses in electrical distribution system and also attain quality power supply. If proper selection and placement of capacitor is not done then it behaves in abnormal way and voltage drops may increase beyond limits and effects the system with more power losses with poor voltage profile at each load bus. Considering the above problems, many researchers are working for the best solution using various methods. Among them some of the techniques are taken as main choices like Particle swarm optimization, Genetic Algorithm, Ant colony algorithm, Fuzzy evolutionary programming, simulated annealing etc.

A new approach of using immune based optimization to solve capacitor placement problem [1]. In this paper they considered two methods one is simulated annealing[SA] and other is mixed integer programming, $\mathrm{SA}$ is used to find computation time and system cost whereas mixed integer programming decomposed into two problems, master and slave. The master is used to determine capacitor location and slave is used to find type and size of the capacitors. It is applied for an IEEE-69 test bus system.

Mixed integer programming [2] is used for determining placement of capacitor and its size, but the assumptions made in this are not permissible. Applying loss sensitivity factor and genetic algorithm for calculating location and size of capacitor [3] had shown an improvement in voltage regulation. These methods are applied for an IEEE-34 bus, 15 bus,

and 69 bus test systems. DG placement in distribution network for power loss minimization using genetic algorithm [4].Genetic algorithm is applied for a IEEE-33 bus system where the GA are compared with the results of harmony search algorithm using Matlab.Large number of capacitor banks may reduce reactive power demand from conventional generators, but it can affect generators and transmission line performance. In this power DG's are used with capacities ranging from $1 \mathrm{~kW}$ to $1000 \mathrm{MW}$. To overcome drawbacks like system power less, voltage fluctuation etc.

Reconfiguration of system helped in reducing power loss by $31.05 \%$.Forthcoming methods have shown better result than this by determining optimum capacitor placement in electrical distribution system using loss sensitivity factor [5].In this paper the results are compared with index vector method which showed a better result.

The capacitor placement in electrical distribution system is assessed by using simulated annealing method [6], where it showed $13 \%$ of the power produced in the system wastes as ohmic losses. Here analytical method is used to find capacitor allocation and size. Analytical method is mostly preferred by the researchers as it needs few numerical data from the distribution system and it is easily applied in practice. But it is practically good for determining cost and computation time of the electrical distribution system. In past lot of work has been carried out on the area of reactive power compensation. Recently to obtain optimum values of capacitors researchers are picking up genetic algorithm and simulated annealing [7] for better results.

But genetic algorithm requires high CPU time whereas genetic operations like (selection, crossover and mutation) requires very less time. In an early researcher's 
work fuzzy technique is used for calculating capacitor allocation and size of it [8].It is applied for a radial distribution system, which is popular among all electrical distribution systems based on low cost and simple design. This technique has a disadvantage that it lags with mathematical description. Feeder reconfiguration with dispatch able distributed generators in distribution system by Tabu search [9]. It is applied for a 69 bus system.

In this paper, based on mechanism of evolution immune based optimization is considered for determining capacitor location and size. This paper deals with two methods: Heuristic search is to find optimal capacitor allocation, for determining capacitor size Genetic algorithm is used. Loss sensitivity factor is used through heuristic approach for capacitor allocation based on ranking.

The paper is organized as Chapter-II that states about problem statement, Chapter-III reveals about techniques proposed and Chapter-IV mentions about results and analysis followed by conclusions.

\section{Problem Statement}

Electrical distribution system is growing in large and becoming complex, leading to more real power losses and maximum voltage drop in each branch, this results poor voltage at each load bus. Therefore to minimize this problem, suitable capacitors are to be placed at appropriate locations in electrical distribution system. After calculating optimal size and location of the capacitor, when capacitor is placed at above location with appropriate size the voltage profile gets improved as capacitors inject reactive power at nodes to reduce losses and voltage drop. Capacitor placement is capable to minimize the chance in voltage deviation. When some large or small disturbances occur in the system the voltage will fall, if it declines sharply then it can damage loads that are connected to electrical distribution system. So by installing suitable capacitor at proper location with suitable size, the electrical distribution system attains good quality power supply in terms of voltage.

\section{A. Problem Formulation}

Line losses:

The amount of power that can be transmitted through a material is limited by several factors, including the material itself and the temperature of the environment. This limitation is observed as a decrease in power from the source to the destination, called line loss. The purpose or intention of placing a capacitor at proper location with proper size is to reduce voltage drop at each bus where reactive power compensation is required and minimize real power losses and improve bus voltage.

The real power loss which is expressed as $\left[\mathrm{I}_{\mathrm{k}} \wedge 2\right] * \mathrm{R}_{\mathrm{k}}$ can also be given as,

$$
\begin{gathered}
\mathrm{P}_{\text {loss }}[\mathrm{j}]=\left[\left[\mathrm{P}_{\text {jeff }} \wedge 2+\mathrm{Q}_{\mathrm{jeff}}{ }^{\wedge} 2\right]^{*} \mathrm{R}_{\mathrm{k}}\right] /\left[\mathrm{V}_{\mathrm{j}}{ }^{\wedge} 2\right] \quad \rightarrow(1) \\
\mathrm{Q}_{\text {loss }}[\mathrm{j}]=\left[\left[\mathrm{P}_{\text {jeff }}{ }^{\wedge} 2+\mathrm{Q}_{\text {jeff }} \wedge 2\right] * \mathrm{X}_{\mathrm{k}}\right] /\left[\mathrm{V}_{\mathrm{j}}{ }^{\wedge}\right] \quad \rightarrow
\end{gathered}
$$

Loss sensitivity factor:
It is used to determine proper capacitor allocation. Loss sensitivity factor decides the sequence in which buses are to be considered for capacitor placement. It is used to predict which bus will have the biggest loss reduction when a suitable capacitor is placed. The estimation of buses which require reactive power compensation basically helps in reduction of the search space for the optimization problem. As few number of buses are recommended for compensation with optimal installation cost. Formula for loss sensitivity factor is given by partially differentiating line loss with respect to reactive power,

$$
\frac{\partial \text { Plineloss }}{\partial \mathrm{Q} \text { eff }[\mathrm{j}]}=(2 * \mathrm{Qeff}[\mathrm{j}]) * \frac{R k}{\left[\mathrm{Vj}^{2}\right]} \quad \rightarrow
$$

$$
\frac{\partial \text { Qlineloss }}{\partial \mathrm{Qeff}[\mathrm{j}]}=(2 * \operatorname{Qeff}[\mathrm{j}]) * \frac{X k}{\left[\mathrm{Vj}^{2}\right]}
$$

Where $P_{e f f}[j]=$ Total effective active power supplied beyond the bus' $\mathrm{j}$ '

$Q_{\text {eff }}[j]=$ Total effective reactive power supplied beyond the bus ' $\mathrm{j}$ '

\section{Proposed Method}

Immune algorithm:

Immune algorithm belong to the artificial immune systems field of study concerned with computational methods inspired by the process and mechanisms of the biological immune system.

A simplified description of the immune system is an organ system intended to forefend the host organism from the threats posed to it from pathogens and toxic substances. Pathogens encompass a range of microorganisms such as bacteria, viruses, parasites and pollen.

The traditional perspective regarding the role of the immune system, which is divided into two primary tasks, detection and elimination of pathogens. The architecture of immune system is such that a series of defensive layers forefend the host.

For an immune system operation, the antigens should be eliminated by an antibody. Immune system is composed of organs, cells and tissues including a type of white blood cells called lymphocytes. These lymphocytes acts as antibody and eliminates antigens. Lymphocytes are of two types:

- B-Lymphocytes,

- T-Lymphocytes.

B-Lymphocytes are emerged from bone marrow and T-Lymphocytes from thymus-Lymphocytes are the cells that are alerted when "lamentable agents" enter the system. These lamentable agents have antibodies on their surface which are additionally called as antigens.

T-Lymphocytes come into action when BLymphocytes detect lamentable agents and pass information to take action to T-Lymphocytes. The 
antibody which apperceive antigen is called as epitope. The mechanism of immune system is shown in fig. 1 .

Mechanism of immune system:

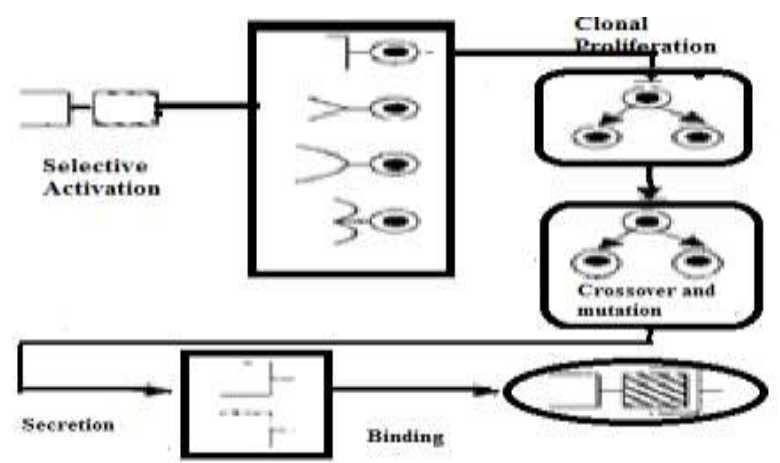

Figure: 1-Immune mechanism

Fundamentally voltage drop is considered as major quandary in electrical distribution system, because it is becoming astronomically immense and involute. Initially calculate genuine reactive power losses at selective activation. After the calculation of reactive power losses lymphocytes that play a vital role in immune system, in this paper loss sensitivity factor is considered as lymphocytes i.e.; Loss sensitivity factor is calculated and given ranking predicated on their rigor in decrementing order(max to $\min )$.The clonal proliferation process detects the affected branch at which capacitor placement is needed. According to biology clonal proliferation process is described as cull and reproduction of only one type of cell. After this process it is given to genetic operations like crossover and mutation where the capacitor size is calculated utilizing genetic algorithm. In this paper the capacitor location and size are considered as antibodies in electrical distribution system. The process secretion engenders antibodies that avail in reducing voltage drop at each branch and decrement authentic power losses by placing opportune capacitor at opportune location with felicitous size. The calculations after placing capacitor shows that the antigens like authentic power losses are reduced and can procure good quality of power supply.

Heuristic search algorithm for capacitor allocation:

Conventional optimization methods face difficulties and often end up by preventing these methods to determine a solution to optimization problem within reasonable period of time. To avoid these cases alternative methods are proposed, which are able to determine solution which are not accurate but they provide quality approximations to exact solutions. These alternative methods are called as heuristics, which are initially and essentially based on expert's knowledge and experience and aimed to explore in a proper and convenient way.

The alternative method used in this paper is loss sensitivity factor for calculating capacitor allocation. The exact bus is predicted after capacitor placement. The following steps are to be performed to find out the potential buses for capacitor placement:

Step-1: Initially calculate line losses as given in equations 1 and 2 .

Step-2: Now calculate loss sensitivity factor at each bus using equations 3 and 4.

Step-3: Among all the values, select few buses based on their severity, and arrange it in a descending order and give ranking for it.

Genetic algorithm for capacitor size:

Implementing genetic algorithm based capacitor sizing. To minimize voltage drop and real power losses calculate optimum values of capacitors that are to be placed at proper location in electrical distribution system.

Algorithm for GA based capacitor sizing:

Step-1: Generate random population at candidate nodes for sizes of capacitors.

Step-2: Perform load flows to determine various node voltages, active power losses.

Step-3: Determine fitness function values.

Step-4: Select parent strings by stochastic universal sampling selection process.

Step-5: Perform crossover and mutation on the selection strings and obtain new strings for next generation.

Step-6: Repeat steps 2 to 5 until the difference between best fitness and average fitness is less than specified error or predefined iterations.

Step-7: Stop.

\section{Flowchart}

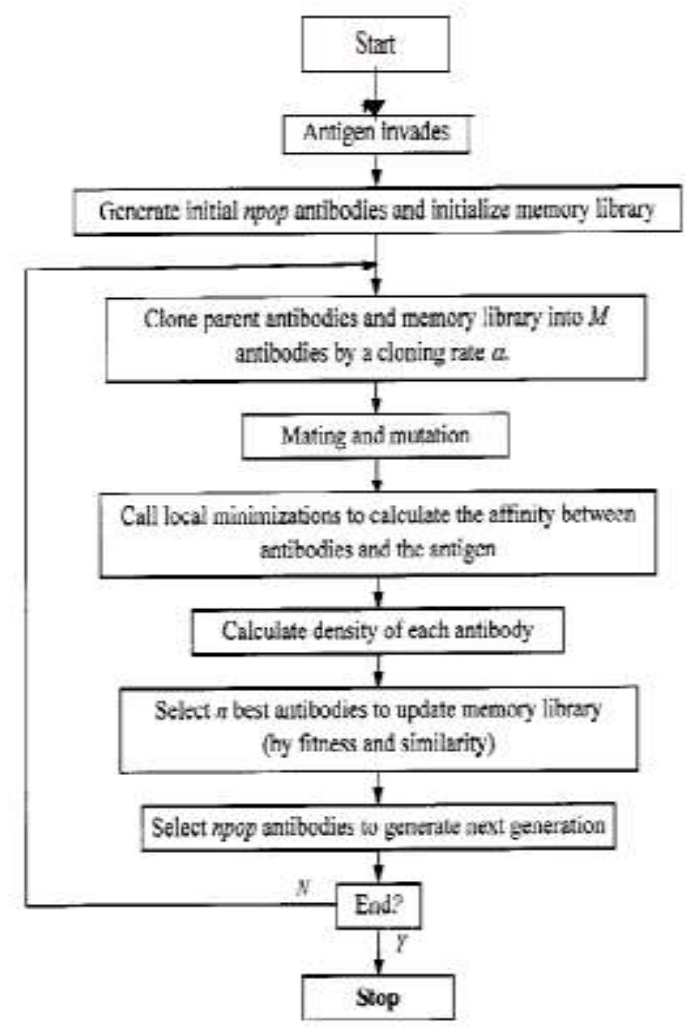


Figure: 2-Flowchart for immune algorithm

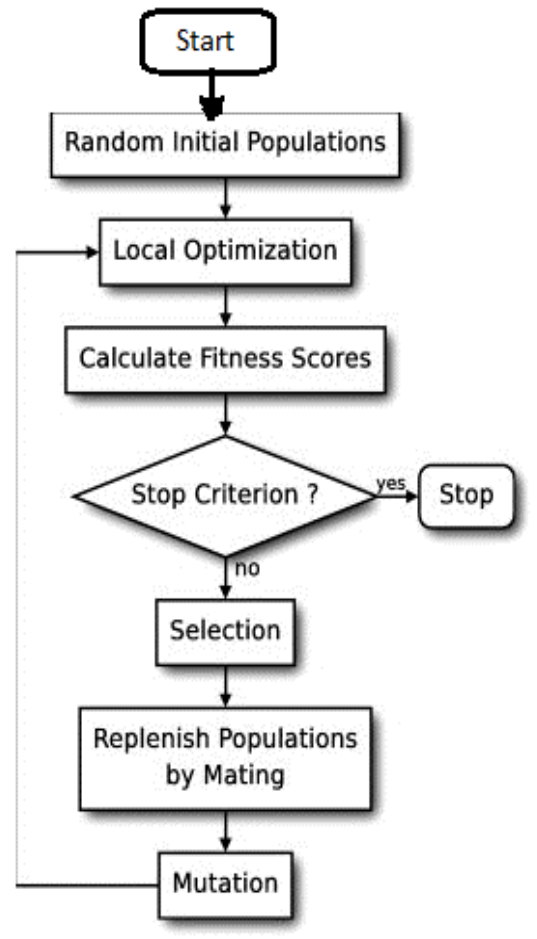

Figure: 3 Flowchart for heuristic method

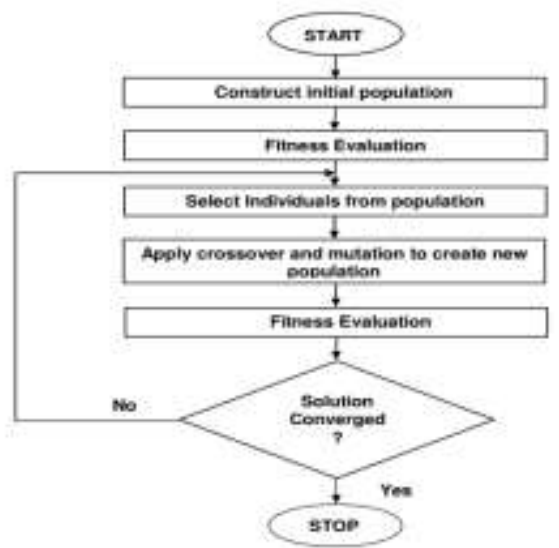

Figure: 4-Flowchart for calculating capacitor size using genetic algorithm

\section{Results and Discussion}

In this chapter Loss sensitivity factor and Genetic algorithm for capacitor allocation and size are discussed.The loss sensitivity factor and Heuristic approach are used to determine the candidate buses for capacitor placement and genetic algorithm is used to find the sizes of shunt capacitors to be installed at candidate buses.fig:2-describes the immune algorithm by using flowchart,and fig:3-represents flowchart that shows step by step procedure of calculating capacitor allocation using heuristic method and fig:4-describes genetic algorithm for calculating capacitor size. Base configuration of IEEE-33 bus system is shown in Fig:5 and table.1 shows the data of testing system. For calculations of IEEE-33 and 69 bus systems the following are considered, that is Base $\mathrm{kV}=12.66$, Base $\mathrm{MVA}=0.1$.Fig- 6 shows Base configuration of 69 bus system.

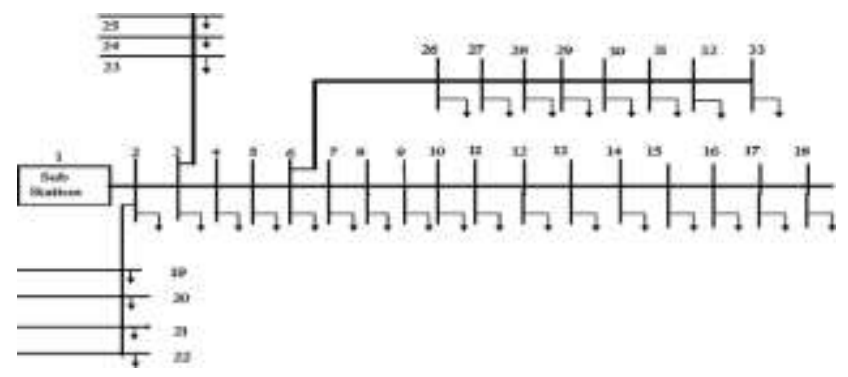

Figure.5- Base configuration of 33-bus system

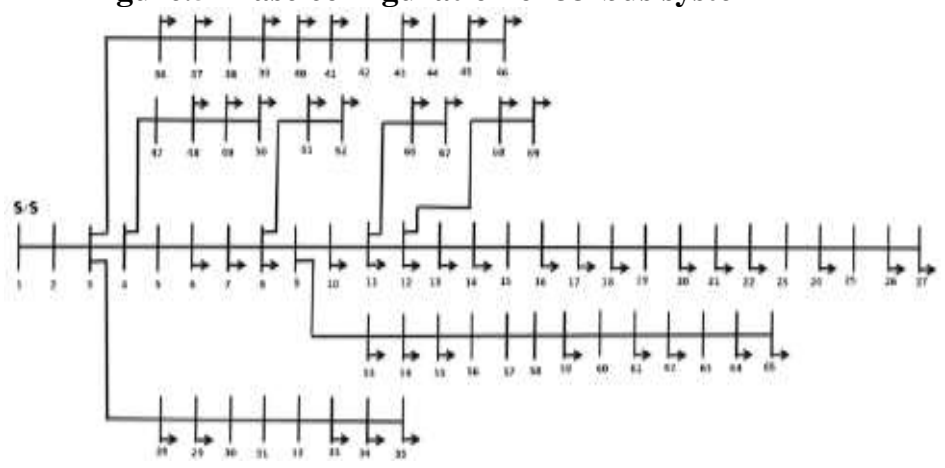

Figure.6- Base configuration of 69-bus system Case-1: 33 bus system

Table 1: Network data for 33-bus system

\begin{tabular}{|c|c|c|c|c|c|c|}
\hline $\begin{array}{c}\text { Line } \\
\text { No. }\end{array}$ & $\begin{array}{c}\text { Bus } \\
(\text { From })\end{array}$ & $\begin{array}{c}\text { Bus } \\
(\mathrm{To})\end{array}$ & $\begin{array}{c}\mathrm{R} \\
(\mathrm{ohm})\end{array}$ & $\begin{array}{c}\mathrm{X} \\
(\mathrm{ohm})\end{array}$ & $\begin{array}{c}\mathrm{P}_{\text {load }} \\
(\mathrm{kW})\end{array}$ & $\begin{array}{c}\mathrm{Q}_{\text {load }} \\
(\mathrm{kVar})\end{array}$ \\
\hline 1 & 1 & 2 & 0.0922 & 0.0477 & 100 & 60 \\
\hline 2 & 2 & 3 & 0.4930 & 0.2511 & 90 & 40 \\
\hline 3 & 3 & 4 & 0.3660 & 0.1840 & 120 & 80 \\
\hline 4 & 4 & 5 & 0.3811 & 0.1941 & 60 & 30 \\
\hline 5 & 5 & 6 & 0.8190 & 0.0700 & 60 & 20 \\
\hline 6 & 6 & 7 & 0.1872 & 0.6188 & 200 & 100 \\
\hline 7 & 7 & 8 & 0.7114 & 0.2351 & 200 & 100 \\
\hline 8 & 8 & 9 & 1.0300 & 0.7400 & 60 & 20 \\
\hline 9 & 9 & 10 & 1.0400 & 0.7400 & 60 & 20 \\
\hline 10 & 10 & 11 & 0.1966 & 0.0650 & 45 & 30 \\
\hline 11 & 11 & 12 & 0.3744 & 0.1238 & 60 & 35 \\
\hline 12 & 12 & 13 & 1.4680 & 1.1550 & 60 & 35 \\
\hline 13 & 13 & 14 & 0.5416 & 0.7129 & 120 & 80 \\
\hline 14 & 14 & 15 & 0.5910 & 0.5260 & 60 & 10 \\
\hline 15 & 15 & 16 & 0.7463 & 0.5450 & 60 & 20 \\
\hline
\end{tabular}




\begin{tabular}{|c|c|c|c|c|c|c|}
\hline 16 & 16 & 17 & 1.2890 & 1.7210 & 60 & 20 \\
\hline 17 & 17 & 18 & 0.7320 & 0.5740 & 90 & 40 \\
\hline 18 & 2 & 19 & 0.1640 & 0.1565 & 90 & 40 \\
\hline 19 & 19 & 20 & 1.5042 & 1.3554 & 90 & 40 \\
\hline 20 & 20 & 21 & 0.4095 & 0.4784 & 90 & 40 \\
\hline 21 & 21 & 22 & 0.7089 & 0.9373 & 90 & 40 \\
\hline 22 & 3 & 23 & 0.4512 & 0.3083 & 90 & 50 \\
\hline 23 & 23 & 24 & 0.8980 & 0.7091 & 420 & 200 \\
\hline 24 & 24 & 25 & 0.8960 & 0.7011 & 420 & 200 \\
\hline 25 & 6 & 26 & 0.2030 & 0.1034 & 60 & 25 \\
\hline 26 & 26 & 27 & 0.2842 & 0.1447 & 60 & 25 \\
\hline 27 & 27 & 28 & 1.0590 & 0.9337 & 60 & 20 \\
\hline 28 & 28 & 29 & 0.8042 & 0.7006 & 120 & 70 \\
\hline 29 & 29 & 30 & 0.5075 & 0.2585 & 200 & 600 \\
\hline 30 & 30 & 31 & 0.9744 & 0.9630 & 150 & 70 \\
\hline 31 & 31 & 32 & 0.3105 & 0.3619 & 210 & 100 \\
\hline 32 & 32 & 33 & 0.3410 & 0.5302 & 60 & 40 \\
\hline 33 & 21 & 8 & 0.0000 & 2.0000 & - & - \\
\hline 34 & 9 & 15 & 0.0000 & 2.0000 & - & - \\
\hline 35 & 12 & 22 & 0.0000 & 2.0000 & - & - \\
\hline 36 & 18 & 33 & 0.0000 & 2.0000 & - & - \\
\hline 37 & 25 & 19 & 0.0000 & 2.0000 & - & - \\
\hline
\end{tabular}

Table: 2 Represents real power loss calculations before and after capacitor placement.

\begin{tabular}{|c|c|c|c|c|}
\hline $\begin{array}{l}\text { Bus } \\
\text { no. }\end{array}$ & $\begin{array}{l}\text { Voltage at } \\
\text { each bus } \\
(\mathrm{kV})\end{array}$ & $\begin{array}{c}\text { Voltage } \\
\text { difference }\end{array}$ & $\begin{array}{l}\text { Ploss }(\mathrm{kW}) \\
\text { before } \\
\text { capacitor } \\
\text { placement }\end{array}$ & $\begin{array}{c}\mathrm{P}_{\text {loss }}(\mathrm{kW}) \\
\text { after capacitor } \\
\text { placement }\end{array}$ \\
\hline 1 & 12.66 & 0.0009 & 11.360 & 8.3610 \\
\hline 2 & 12.659 & 0.0041 & 58.082 & 42.4269 \\
\hline 3 & 12.655 & 0.004 & 43.119 & 31.4975 \\
\hline 4 & 12.651 & 0.002 & 41.966 & 30.2983 \\
\hline 5 & 12.649 & 0.004 & 90.188 & 65.1123 \\
\hline 6 & 12.645 & 0.004 & 19.960 & 14.3283 \\
\hline 7 & 12.641 & 0.011 & 73.550 & 52.5003 \\
\hline 8 & 12.629 & 0.006 & 95.099 & 67.4163 \\
\hline 9 & 12.623 & 0.005 & 96.022 & 68.0709 \\
\hline 10 & 12.618 & 0.001 & 16.100 & 11.1501 \\
\hline 11 & 12.617 & 0.002 & 29.596 & 20.3503 \\
\hline 12 & 12.615 & 0.008 & 111.948 & 76.3997 \\
\hline 13 & 12.607 & 0.0055 & 40.029 & 27.1375 \\
\hline 14 & 12.6015 & 0.0035 & 41.929 & 28.1740 \\
\hline 15 & 12.598 & 0.004 & 50.781 & 34.0390 \\
\hline 16 & 12.594 & 0.006 & 80.184 & 53.6652 \\
\hline 17 & 12.588 & 0.0054 & 43.789 & 29.0506 \\
\hline 18 & 12.5826 & 0.0041 & 9.412 & 6.18471 \\
\hline 19 & 12.655 & 0.012 & 82.747 & 53.9674 \\
\hline 20 & 12.643 & 0.003 & 21.049 & 13.5033 \\
\hline 21 & 12.640 & 0.0052 & 79.773 & 58.0672 \\
\hline 22 & 12.6348 & 0.0036 & 48.443 & 34.9740 \\
\hline 23 & 12.6514 & 0.0334 & 91.883 & 66.0709 \\
\hline 24 & 12.618 & 0.033 & 78.013 & 55.4432 \\
\hline 25 & 12.585 & 0.0033 & 13.534 & 9.4237 \\
\hline 26 & 12.6417 & 0.00146 & 25.359 & 17.8615 \\
\hline 27 & 12.64024 & 0.00534 & 91.356 & 63.9262 \\
\hline 28 & 12.6349 & 0.0089 & 64.279 & 44.8495 \\
\hline 29 & 12.626 & 0.0254 & 27.463 & 24.61196 \\
\hline 30 & 12.6006 & 0.0136 & 46.942 & 42.2414 \\
\hline 31 & 12.587 & 0.0049 & 12.545 & 11.1773 \\
\hline 32 & 12.5821 & - & 13.003 & 11.54483 \\
\hline
\end{tabular}

Table 3: Represents capacitor size and connected load using loss sensitivity factor

\begin{tabular}{|c|c|c|c|c|c|}
\hline S.no & $\begin{array}{c}\text { Bus } \\
\text { no. }\end{array}$ & L.S.F & Ranking & $\begin{array}{c}\text { Capacitor } \\
\text { size in } \\
\text { (kVAR) }\end{array}$ & $\begin{array}{c}\text { Connected } \\
\text { load } \\
\text { (kVA) }\end{array}$ \\
\hline 1 & 29 & 1.945 & 1 & 289.5203 & 632.455 \\
\hline 2 & 23 & 1.772 & 2 & 263.7686 & 465.1881 \\
\hline 3 & 24 & 1.761 & 3 & 262.1312 & 465.1881 \\
\hline 4 & 30 & 0.849 & 4 & 126.3767 & 165.5294 \\
\hline 5 & 6 & 0.774 & 5 & 115.2127 & 223.6067 \\
\hline 6 & 13 & 0.717 & 6 & 106.7280 & 144.2220 \\
\hline 7 & 19 & 0.677 & 7 & 100.7739 & 98.4885 \\
\hline 8 & 28 & 0.614 & 8 & 91.45568 & 138.9244 \\
\hline 9 & 12 & 0.508 & 9 & 75.61765 & 69.46221 \\
\hline 10 & 21 & 0.469 & 10 & 69.81236 & 98.4885 \\
\hline 11 & 16 & 0.434 & 11 & 64.6024 & 63.24555 \\
\hline
\end{tabular}

Table 2 reveals real power losses before and after placement of capacitor in 33 bus system. Table 3 shows loss sensitive factor, ranking based on severity along with capacitor size for compensation. From fig. 7 it is observed that real power losses get reduced considerably and from fig. 8 commendable improvement in voltages at each bus after capacitor placement.

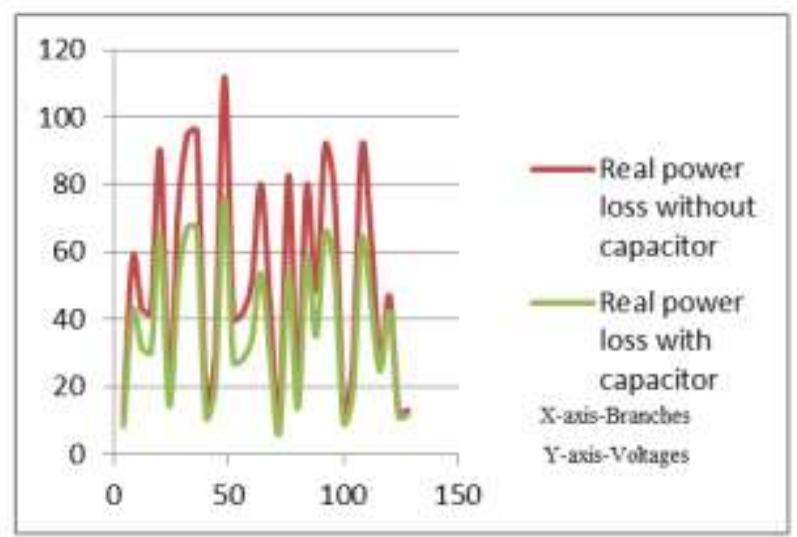

Figure:7 Real power losses before and after capacitor placement

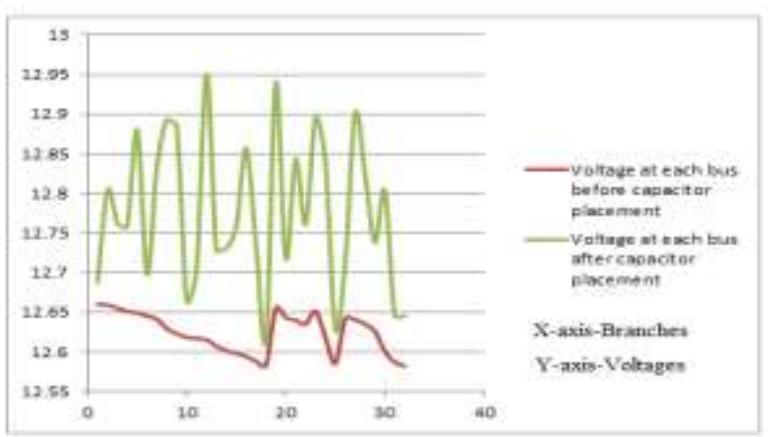

Figure.8-Load Bus voltages before and after capacitor placement 
Case-2: 69 bus system

Table:6- Represents real power loss calculations before and after capacitor placement of 69-bus system

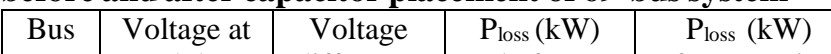

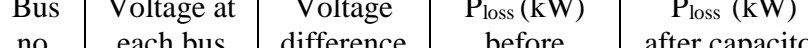

\begin{tabular}{|c|c|c|c|c|}
\hline no. & $\begin{array}{l}\text { each bus } \\
(\mathrm{kV})\end{array}$ & aimerence & $\begin{array}{c}\text { berore } \\
\text { capacitor } \\
\text { placement }\end{array}$ & $\begin{array}{l}\text { atter capacito } \\
\text { placement }\end{array}$ \\
\hline 1 & 12.6600 & 0 & 0.06791 & 0.04822 \\
\hline
\end{tabular}

\begin{tabular}{|c|c|c|c|c|}
\hline 58 & 12.6543 & 0.003 & 34.49763 & 24.398955 \\
\hline 59 & 12.6513 & 0 & 43.7854 & 30.9679055 \\
\hline 60 & 12.6513 & 0.0613 & 23.66567 & 17.345052 \\
\hline 61 & 12.5900 & 0.000299 & 4.41122 & 3.21711 \\
\hline 62 & 12.5897 & 0 & 6.56702 & 4.7893368 \\
\hline 63 & 12.5897 & 0.0157 & 25.8283 & 19.0416024 \\
\hline 64 & 12.5740 & 0.006 & 35.59096 & 26.3147156 \\
\hline 65 & 12.5680 & 0.01 & 21.01615 & 15.0054858 \\
\hline 66 & 12.6428 & 0 & 0.48561 & 0.34603190 \\
\hline 67 & 12.6428 & 0.0008 & 76.8667 & 54.8347419 \\
\hline 68 & 12.6420 & - & 0.48038 & 0.3416247 \\
\hline
\end{tabular}

\begin{tabular}{|l|l|l|l|l|l}
\hline 3 & 12.6600 & 0 & 0.20374 & 0.14468 & 67 \\
\hline 4 & 12.6600 & 0 & 3.40939 & 2.42114 & 68 \\
\hline 5 & 12.6600 & 0.00099 & 49.6421 & 35.24320 &
\end{tabular}

\begin{tabular}{|l|l|l|l|l|}
\hline 5 & 12.6600 & 0.00099 & 49.6421 & 35.24320 \\
\hline 6 & 12.6590 & 0.001 & 50.5803 & 35.94422 \\
\hline
\end{tabular}

Table: 7- Represents capacitor size and

\begin{tabular}{|l|l|l|l|l|}
\hline 7 & 12.6580 & 0.00099 & 11.75140 & 8.3632 \\
\hline 8 & 12.6570 & -0.0005 & 6.180525 & 4.38503 \\
\hline 9 & 12.6575 & 0.0025 & 101.129848 & 71.76738 \\
\hline 10 & 12.6550 & 0.0022 & 21.2975 & 15.15840 \\
\hline
\end{tabular}

\begin{tabular}{|l|l|l|l|l|}
\hline 9 & 12.6575 & 0.0025 & 101.129848 & 71.76738 \\
\hline 10 & 12.6550 & 0.0022 & 21.2975 & 15.15840 \\
\hline 11 & 12.6528 & 0.01 & 74.30860 & 53.05617 \\
\hline 12 & 12.6428 & 0.0008 & 107.077035 & 76.38596 \\
\hline 13 & 12.6420 & 0.00099 & 108.01607 & 76.98817 \\
\hline
\end{tabular}
\begin{tabular}{|l|c|c|c|c|c|}
\multicolumn{5}{|c}{ connected load using loss sensitivity factor } \\
\hline S.No & $\begin{array}{c}\text { Bus } \\
\text { no. }\end{array}$ & L.S.F & $\begin{array}{c}\text { Rankin } \\
\text { g }\end{array}$ & $\begin{array}{c}\text { Capacitor } \\
\text { size(kVAR }\end{array}$ & $\begin{array}{c}\text { Connected } \\
\text { load(kVA) }\end{array}$
\end{tabular}

\begin{tabular}{|l|l|l|l|l|}
\hline 12 & 12.6428 & 0.0008 & 107.077035 & 76.38596 \\
\hline 13 & 12.6420 & 0.00099 & 108.01607 & 76.98817 \\
\hline 14 & 12.6410 & 0 & 109.46456 & 78.02058 \\
\hline
\end{tabular}

\begin{tabular}{|l|l|l|l|l|}
\hline 14 & 12.6410 & 0 & 109.46456 & 78.02058 \\
\hline 15 & 12.6410 & 0.00099 & 19.79933 & 14.04126 \\
\hline 16 & 12.6400 & 0.002 & 36.41077 & 25.7962 \\
\hline 17 & 12.6380 & 0 & 0.441109 & 0.3104 \\
\hline
\end{tabular}

\begin{tabular}{|c|c|c|c|c|c|c|c|c|c|c|}
\hline 17 & 12.6380 & 0 & 0.441109 & 0.3104 & 7. & 47 & 0.146598 & 7 & 28.35736 & 97.0667811 \\
\hline 18 & 12.6380 & 0 & 30.74629 & 21.6363 & 8. & 20 & 0.114506 & 8 & 22.14960 & 139.846344 \\
\hline 19 & 12.6380 & -0.00029 & 19.75357 & 13.89911 & 9. & 33 & 0.098669 & 9 & 19.08621 & 24.0052077 \\
\hline 20 & 12.6383 & 0.0038 & 29.7675 & 20.98796 & & & 3 & & & \\
\hline
\end{tabular}

\begin{tabular}{|c|c|c|c|c|c|c|c|c|c|c|}
\hline 20 & 12.6383 & 0.0038 & 29.7675 & 20.98796 & & & 3 & & & \\
\hline 21 & 12.6345 & 0 & 1.21599 & 0.8568 & 10. & 58 & 0.090465 & 10 & 17.49920 & 123.223374 \\
\hline 22 & 12.6345 & 0 & 13.81885 & 9.73707 & 11. & 10 & 0.08039 & 11 & 15.55033 & 178.440466 \\
\hline 23 & 12.6345 & 0.0015 & 29.5250 & 20.72981 & 12. & 6 & 0.07267 & 12 & 14.05700 & 50.3205723 \\
\hline 24 & 12.6330 & -0.0005 & 63.84164 & 44.82382 & 13. & 9 & 0.06420 & 13 & 12.41860 & 33.8378486 \\
\hline 25 & 12.6335 & 0.000399 & 26.0912 & 18.285750 & \multirow[t]{2}{*}{14.} & \multirow[t]{2}{*}{67} & 0.061161 & \multirow[t]{2}{*}{14} & \multirow[t]{2}{*}{11.83075} & \multirow[t]{2}{*}{34.4093010} \\
\hline 26 & 12.6331 & 0.0002 & 14.49258 & 10.138349 & & & 0 & & & \\
\hline 27 & 12.6329 & 0 & 0.59766 & 0.42442 & 15. & 16 & 0.05424 & 15 & 10.49198 & 69.4622199 \\
\hline 28 & 12.6600 & 0.0002 & 8.5745600 & 6.09080 & 16. & 44 & 0.04506 & 16 & 8.716235 & 47.2218000 \\
\hline 29 & 12.6598 & 0 & 53.29624 & 37.85815 & \multirow[t]{2}{*}{17.} & \multirow[t]{2}{*}{28} & 0.036323 & \multirow[t]{2}{*}{17} & \multirow[t]{2}{*}{7.02629} & \multirow[t]{2}{*}{31.9681091} \\
\hline 30 & 12.6598 & 0 & 9.40523 & 6.68085 & & & 6 & & & \\
\hline 31 & 12.6598 & 0.0008 & 47.02610 & 33.40425 & 18. & 36 & 0.036226 & 18 & 7.00742 & 31.9390435 \\
\hline 32 & 12.6590 & 0.0012 & 111.57392 & 79.273719 & \multirow[t]{2}{*}{19.} & \multirow[t]{2}{*}{32} & 0.035145 & \multirow[t]{2}{*}{19} & \multirow[t]{2}{*}{6.798315} & \multirow[t]{2}{*}{17.2046505} \\
\hline 33 & 12.6578 & 0.0032 & 224.781076 & 159.74959 & & & 0 & & & \\
\hline 34 & 12 & 0.000 & 193.3766 & 137.35024 & 20. & 7 & 0.03168 & 20 & 6.128059 & 92.4175308 \\
\hline
\end{tabular}

\begin{tabular}{|l|l|l|l|l|}
\hline 34 & 12.6546 & 0.0008 & 193.3766 & 137.35024 \\
\hline 35 & 12.6538 & 0 & 0.59766 & 0.42442 \\
\hline 36 & 12.6600 & 0.0002 & 8.57466 & 6.090830 \\
\hline 37 & 12.6598 & 0 & 14.10800 & 10.021320 \\
\hline
\end{tabular}

\begin{tabular}{l|l|l|}
\hline 1. & 60 & 2.868356 \\
\hline
\end{tabular}

\begin{tabular}{l|c}
$\mathrm{g}$ & $\mathrm{size}(\mathrm{kV}$ \\
\hline 1 & 554.843 \\
\hline
\end{tabular}

\begin{tabular}{|l|l|l|l|l|l|}
\hline 2. & 48 & 2.429184 & 2 & 469.89214 & 472.593207 \\
\hline 3. & 63 & 0.739780 & 3 & 143.10023 & 278.878109 \\
\hline
\end{tabular}

\begin{tabular}{|l|l|l|l|l|l|}
\hline 2. & 48 & 2.429184 & 2 & 469.89214 & 472.593207 \\
\hline 3. & 63 & 0.739780 & 3 & 143.10023 & 278.878109 \\
\hline
\end{tabular}

\begin{tabular}{l|l}
\hline 84391 & 1528.42402 \\
\hline
\end{tabular}

5.

4. 5.


Table-6 reveals real power losses before and after placement of capacitor in 69 bus system. Table 7 shows loss sensitivity factor, ranking based on severity along with capacitor size for compensation, and Table 8 reveals the test results of 33 and 69 bus systems before and after placement of capacitors and Table 9 reveals the comparisons between methods applied for a 33 and 69 bus systems before and after capacitor placement and reduction in percentage of real power losses. From this it is observed that the power loss regulation is reduced in proposed method compared to other methods which show an eminent performance of the system by providing best quality of power. From fig.9 commendable improvement in voltages at each bus after capacitor placement and from fig.10 it is observed that real power losses get reduced considerably.

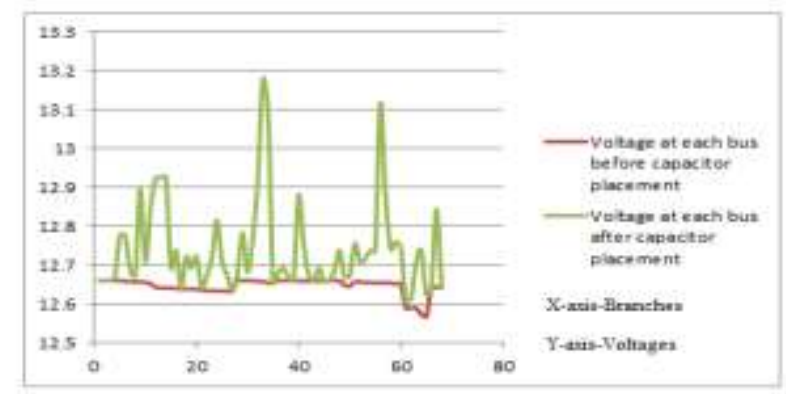

Figure: 9-Load Bus voltages before and after capacitor placement

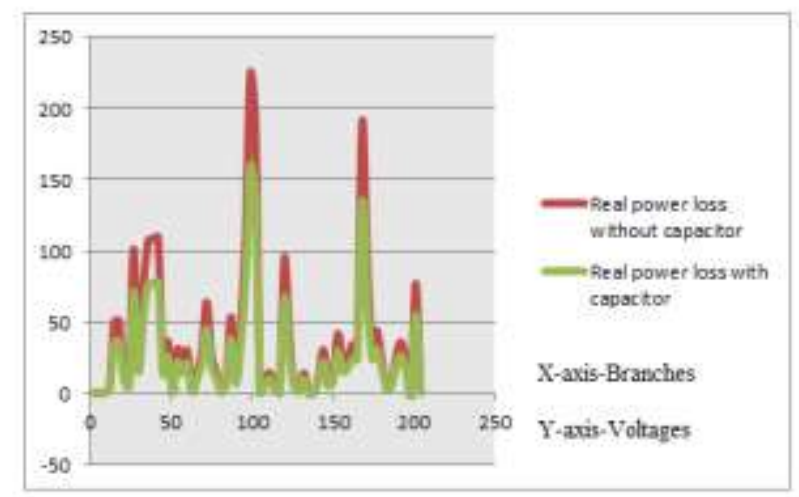

Figure: 10- Real power losses before and after capacitor placement

\section{Conclusion}

In this paper a new approach of immune based optimization is introduced. For voltage drop reduction and minimization of power loss a pre-eminent approach is done using heuristic and genetic algorithm. The performances before and after proper placement of capacitor drastically improved.

\section{References}

1. Shyh-Jier Huang, "An Immune-Based Optimization Method to Capacitor Placement in a Radial Distribution System" Member, IEEE 744 IEEE TRANSACTIONS ON POWER DELIVERY, VOL. 15, NO. 2, APRIL 2000.

2. M. Kaplan, "Optimization of Number, Location, Size, Type, and Control Setting of
Shunt Capacitors on Radial Distribution Feeders,"IEEE Transactions on Power Apparatus and Systems, vol. 103, no. 9,pp. 2659-2665, September 1984.

3. Y. G. Bae, "Analytical Method of Capacitor Allocation on Distribution Primary Feeders," IEEE Transactions on Power Apparatus and Systems, vol. 97, no. 4, pp. 1232-1238, July/August 1978.

4. H. Duran, "Optimum Number, Location, and Size of Shunt Capacitors in Radial Distribution Feeder: A Dynamic Programming Approach,"IEEE Transactions on Power Apparatus and Systems, vol. 87, no. 9, pp.17691774, September 1968.

5. J. J. Grainger and S. H. Lee, "Capacity Release by Shunt Capacitor Placement on Distribution Feeders: A New Voltage Dependent Model,"IEEE Transactions on Power Apparatus and Systems, vol. 101, pp.12361244, May 1982.

6. M. A. EI-Sharkawi and S. J. Huang, "Ancillary Technique for Neural Network Applications," in IEEE International Conference on Neural Networks, Orlando, Florida, USA, June 1994.

7. J. Huang and C. L. Huang, "Application of Genetic-Based Neural Networks to Thermal Unit Commitment," IEEE 4950Transactions on Power Systems, vol. 12, no. 2, pp. 654-660, May 1997.

8. M. E. Baran and F. F. Wu, "Optimal Capacitor Placement on Radial Distribution Systems," IEEE Transactions on Power Delivery, vol. 4, no. 1, pp. 725-734, January 1989.

9. N. Rugthaicharoencheep, and S. Sirisumrannukul, "Feeder

10. Reconfiguration with dispatchable distributed Generators in

11. Distribution system by Tabu search".

12. Mohammad H. Moradi, Arash Zeinalzadeh,Younes Mohammadi, and Mohammad Abedini "An efficient hybrid method for solving the optimal sitting and sizing problem of DG and shunt capacitor banks simultaneously based on imperialist competitive algorithm and genetic algorithm" International Journal of Electrical Power and Energy Systems-January 2014.

13. Moradi MH, Abedini M "A combination of genetic algorithm and particle swarm optimization for optimal DG location and sizing in distribution systems "International Journal of Electrical Power Energy Systems 2012; 34(1):66-74. 